\title{
DÜBLIN
}

Technological University Dublin

ARROW@TU Dublin

Conference Papers

School of Physics \& Clinical \& Optometric

Science

2000

\section{Development of an Amperometric Biosensor for Lactate.}

\author{
Brian Lillis \\ UCC, blillis@ucc.nmrc.ie \\ Catherine M. Grogan \\ Technological University Dublin, catherine.grogan@tudublin.ie \\ Helen Berney \\ UCC - Nursing School
}

See next page for additional authors

Follow this and additional works at: https://arrow.tudublin.ie/scschphycon

Part of the Other Medical Sciences Commons

\section{Recommended Citation}

Lillis, B., Grogan, C., Berney, H. and Lane, B. Development of an Amperometric Biosensor for Lactate. 1'st Annual International IEEE-EMBS Special Topic Conference on Microtechnologies in Medicine \& Biology October 12-14,2000, Lyon, France doi.org/10.21427/b3x0-t150

This Conference Paper is brought to you for free and open access by the School of Physics \& Clinical \& Optometric Science at ARROW@TU Dublin. It has been accepted for inclusion in Conference Papers by an authorized administrator of ARROW@TU Dublin. For more information, please contact arrow.admin@tudublin.ie, aisling.coyne@tudublin.ie,gerard.connolly@tudublin.ie.

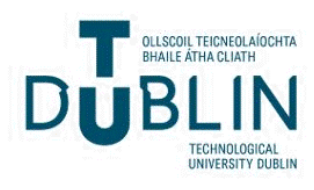




\section{Authors}

Brian Lillis, Catherine M. Grogan, Helen Berney, and Bill Lane 


\title{
DEVELOPMENT OF AN AMPEROMETRIC BIOSENSOR FOR LACTATE
}

\author{
Brian Lillis (1), Catherine Grogan (2), Helen Berney (1) and Bill Lane (1)
}

(1) NMRC, Lee Maltings, Prospect Row, Cork, Ireland --Tel +353 (0)21 4904112 , Fax +353(0)21 4270273, Email brian.lillis@nmrc.ie, helen.berney@nmrc.ie, blane@nmrc.ie

(2) Department of Physics, University College Galway, Ireland.

\begin{abstract}
A gold enzyme electrode for lactate, fabricated on silicon has been developed. Standard silicon processing and micromachining techniques have been applied to the fabrication of three sensor types. Two planar types and a containment sensor are presented. The enzyme lactate oxidase (LOx) was immobilised in a suitable matrix and placed on a planar gold electrode or in a gold coated, $\mathrm{KOH}$ etched silicon cavity. Activity and stability of the enzyme LOx was assessed in a modified BSA gel and two sol gel matrices. The enzyme has shown above average stability of three months, stored dry, when immobilised in a sol gel matrix. The modified BSA gel also showed potential for use with a gold enzyme electrode. A three electrode configuration in the amperometric mode was used to detect lactate. A linear range of up to $10 \mathrm{mM}$ lactate has been observed using a sol gel as an immobilisation matrix, and a response time as low as $\mathbf{4 0}$ seconds. A modified BSA gel has shown a linear range of up to $12 \mathrm{mM}$ lactate. Lactate has also been successfully detected using the containment sensor.
\end{abstract}

\section{INTRODUCTION}

Lactate, besides glucose and urea, belongs to substrates of enzymatic reactions, which are most often determined in clinical analysis and biotechnology. Lactate determination has significant importance in critical care [1]. Because of the involvement of lactate in several diseases, there are strong demands for the development of reliable amperometric sensors for decentralised lactate monitoring. In critically ill patients a lactate concentration of less than 2 $\mathrm{mM}$ is considered normal [2]. Increased lactate levels reflect an imbalance between lactate production, which serves as an indication of inadequate tissue oxygenation. Therefore, measurement of lactate levels has prognostic significance. Levels of lactate greater than $4 \mathrm{mM}$ have been shown to be associated with circulatory failure, cardiac arrest and in emergency department patients. Lactate sensors have also found use in sports medicine, where it is used as a metabolic variable to indicate the capability of muscles for an athletic performance[3].

In recent years, much research has been perfomed into the development of miniaturised sensors for lactate. Thin film electrode sensors, which can be used in catheters for in vivo lactate analysis, have received considerable attention
[4]. Disposable sensors that can be used for on site analysis have also been developed [5].

Thin film silicon technology represents an attractive use for the microfabrication of such biosensors. Such fabrication technology couples various processes used in the manufacture of electronic circuits, including film deposistion, photolithographic patterning and etching [6]. It offers a greater resolution, and is particularly suited to high volume, low cost production, which has application in sensor arrays.

In this work, different aspects of silicon technology have been applied for fabrication of three different sensor types for lactate. Standard planar processes are applied for fabrication of sensor type A and B. A simple and stable method of packaging the sensor dies was found by placing them on a dipstick printed circuit board (PCB). Micromachining techniques have been applied for the development of sensor type $\mathrm{C}$, which has an anisotropically etched cavity in silicon onto which gold has been evaporated.

The process technology of anisotropic $\mathrm{KOH}$ etching of (100) silicon was used to produce a truncated pyramid shaped cavity. Anisotropic KOH etching has been used extensively in microelectromechanical systems (MEMS) to fabricate bulk micromachined sensors and actuators. $\mathrm{KOH}$ is particularly attractive because of its high etch ratio between the (111) and (100) silicon planes [7]. Anisotropic etching of single crystal silicon, resulting from the differential etch rate of its crystallographic planes, has been used to fabricate a variety of three dimensional device structures. The enzyme has been placed in a suitable matrix in the pyramidal cavity. A separate package for the sensor has been designed.

Stability of the enzyme remains a problem with the development of lactate oxidase (LOX) based sensors [8]. Several immobilisation strategies have been employed to increase stability of the enzyme. These include crosslinking of the enzyme [9], immobilisation of the enzyme in an electrosynthesised film [10] and encapsulation of the enzyme in a carbon paste [11]. However, there is still a long way to go to improve both stability and selectivity of the enzyme in these matrices. Several immobilisation methods are reported here in an effort to increase long term stability of the enzyme LOx. These include encapsulation in a sol gel matrix, crosslinking in a modified BSA gel and immobilisation in a polycarbamoylsulphate (PCS) hydrogel. Particular

$3941^{\text {st }}$ Annual International IEEE-EMBS Special Topic Conference on Microtechnologies in Medicine \& Biology October 12-14, 2000, Lyon, France - 0-7803-6603-4/00/\$10.00@2000 IEEE 
attention has been paid to the potential use of a sol gel as a possible means of enzyme encapsulation.

Sol gel processing has emerged in recent years as an immobilisation method offering excellent potential in the field of biosensor development. This is due to the rigid nature of the sol gel matrix, the mild processing conditions involved which are suitable for biomolecule immobilisation and the chemical inertness of the sol gel material [12]. Activity and stability of the enzyme LOx has been assessed in each matrix, using an enzyme linked immunosorbent assay (ELISA method) prior to assessing their behaviour under amperometric conditions.

\section{EXPERIMENTAL}

\section{A. Sensor Fabrication and Packaging}

The following procedure was applied for the fabrication of sensor type A. The starting material was silicon (100) with a thickness of $525 \mu \mathrm{m}$. A $300 \mathrm{~nm}$ thermal oxide was then grown in a furnace. This oxide layer acts as an insulating layer between the silicon and the metal layers. A $35 \mathrm{~nm}$ thick chrome layer and $250 \mathrm{~nm}$ gold layer were then evaporated onto the silicon dioxide. The chrome layer provided an adhesion layer between the oxide and the gold. The unpatterned gold plated wafer was sawn into square chips with dimensions of $4 \mathrm{~mm} \times 4 \mathrm{~mm}$.

For the fabrication of sensor type $B$, the procedure was as for sensor type A. However, after gold evaporation, Eagle $2100 \mathrm{AD}$ photoresist (Shipley Europe Ltd, England) was electroplated onto the gold. A potential of $50 \mathrm{~V}$ was applied between the wafer, acting as the cathode, and the anode which is a stainless steel sheet of similar area to the wafer. The electrodes were placed in a resist bath, which was then heated to $30^{\circ} \mathrm{C}$. The electrodes were separated by a distance of $7.5 \mathrm{~cm}$. The potential was then applied for a period of 20s. After deposition, the wafers were rinsed thoroughly in DI water and then placed in a convection oven, at $60^{\circ} \mathrm{C}$, for 30 minutes to remove excess moisture and to improve film adhesion. The photoresist was then patterned by exposing to broadband UV at $20 \mathrm{mWcm}^{2}$ for 60 s through the second and third photolithographic masks. The mask was designed to produce a patterned metal line coming from the eiectrode to a single or pair of bond pads for each device. Photoresist, which was not exposed through the photolithography mask, was removed by placing in Shipley 2005 developer for 2-3 minutes and heating to $40^{\circ} \mathrm{C}$. The gold was then pattemed using a solution of $\mathrm{KI}, \mathrm{I}_{2}$ and $\mathrm{H}_{2} \mathrm{O}$. The resist was then stripped using EAGLE 2010 remover (Shipley). The chrome was then subsequently removed using a solution of $\mathrm{K}_{3} \mathrm{FeCN}_{6}$, $\mathrm{NaOH}$ and $\mathrm{H}_{2} \mathrm{O}$.

The result of these process steps produced a silicon die with layers of oxide, chrome and a patterned gold counter and working electrode each with a separate metal line and bond pad. Each silicon die was packaged on a dipstick type PCB (figure 1) (ILFA, Dresden). The die was attached to the dipstick by use of a suitable adhesive.

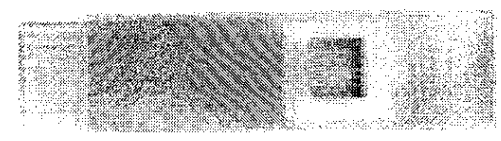

Figure $1 \mathrm{~A}$ picture of the dipstick $\mathrm{PCB}$ used for the packaging of sensor types $A$ and $B$.

For sensor type $A$, only one wire bond was required and this was placed between the second connector and the gold surface. The wire bond and bond pads were encapsulated using a suitable epoxy resin. A picture of the packaged sensor $\mathrm{A}$ is shown in figure 2 .

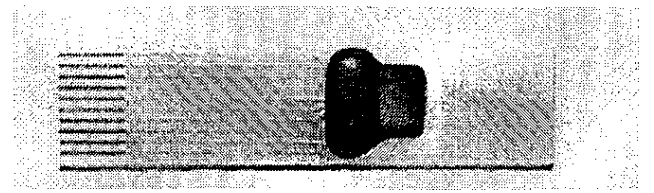

Figure 2 A picture of sensor type A, unpatterned gold on silicon working electrode, packaged on a dipstick.

For sensor type B, gold wire bonds were placed between the second and ninth connectors of the dipstick and the bonds pads of the working and counter electrode, (Towcester Technical Services, England). The wire bonds and bond pads were encapsulated using a suitable epoxy resin. A picture of sensor type B is show in figure 3 .

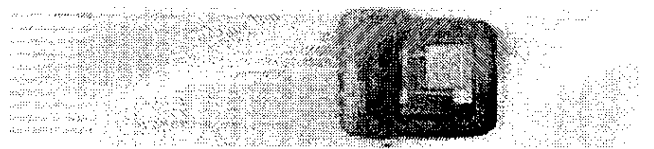

Figure 3 A picture of sensor type B, patterned gold on silicon electrodes (working and counter), packaged on a dipstick.

For sensor type $\mathrm{C}$ a $60 \mathrm{~nm}$ silicon nitride $\left(\mathrm{Si}_{3} \mathrm{~N}_{4}\right)$ was deposited by low pressure chemical vapour deposition on a 4 inch, 525 MM thick (100) silicon wafer. Photoresist was then deposited on the nitride and patterned by exposure to ultraviolet light, through the crystal field alignment mask. The nitride was patterned using a plasma etch process. This patterned nitride layer formed the $\mathrm{KOH}$ etch mask. The silicon wafers were then etched for 13 minutes in $30 \%$ $\mathrm{KOH}$ at $79^{\circ} \mathrm{C}$ to form the square alignment aids which are used to determine the crystal $(110)$ direction to $t-0.1^{\circ}$ Following the $\mathrm{KOH}$ etch, the wafers were cleaned to remove any remaining potassium. $\mathrm{Si}_{3} \mathrm{~N}_{4}$ was again deposited by LPVCD as described. Alignment of the second cavity mask to the (110) mask is carried out. The wafers are etched for 8 hours in $30 \% \mathrm{KOH}$ at $79^{\circ} \mathrm{C}$, producing the desired micromachined cavities. The wafers were cleaned to remove any remaining potassium. A $300 \mathrm{~nm}$ thermal oxide layer is then grown on the wafers in a furnace, a $35 \mathrm{~nm}$ chrome layer and $250 \mathrm{~nm}$ gold layer are then evaporated onto the silicon. The gold wafer was then sawn to produce the desired $6 \times 4 \mathrm{~mm}$ sensor dies. A Perspex package was designed for the device. Cavities of different shapes and dimensions were produced. A picture of packaged sensor $\mathrm{C}$ is shown in figure 4 . 


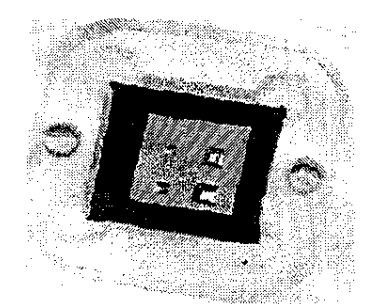

Figure 4 A picture of sensor type $C$, gold electrode in silicon cavities, packaged in a perspex holder.

\section{B. Immobilisation of LOx in Sol Gel 1}

To $2.24 \mathrm{ml}$ of TEOS and $450 \mu$ of ethanol was added $985 \mu \mathrm{l}$ of distilled, de-ionised water and $145 \mu \mathrm{l}$ of $0.1 \mathrm{M}$ $\mathrm{HCl}$. This was mixed in a closed container for 20 minutes until a clear homogeneous solution was observed. To this solution was added $100 \mu \mathrm{l}$ of $1 \mathrm{mgml}^{-1}$ LOx. Volumes of $100 \mu l$ of the solution were aliquoted in triplicate into the wells of a 96 well plate. The sol gel was allowed to dry at $4^{\circ} \mathrm{C}$ and was stored at this temperature between testing. For electrochemical testing, a 70 $\mu$ l volume of the sol gel was mixed with $20 \mu$ of the enzyme solution.

A $10 \mu 1$ volume of the sol-gel enzyme solution was aliquoted onto the surface of sensor type A. A $5 \mu$ l volume was aliquoted on the working electrode of sensor type B and allowed to dry at $4^{\circ} \mathrm{C}$. The sensors were stored in 0.1 $M$ PBS prior to testing.

\section{Immobilisation of LOx in Sol Gel 2}

To $2.24 \mathrm{ml}$ of TEOS and $450 \mu \mathrm{l}$ of dioxane was added $985 \mu \mathrm{l}$ of distilled, de-ionised water and $145 \mu \mathrm{l}$ of $0.1 \mathrm{M} \mathrm{HCl}$. This was mixed in a closed container for 30 minutes until a clear homogeneous solution was observed. To this solution was added $100 \mu \mathrm{l}$ of $1 \mathrm{mgml}^{-1} \mathrm{LOx}$. This was mixed gently. Volumes of $100 \mu \mathrm{l}$ of the solution were aliquoted in triplicate into the wells of a 96 well plate. The sol gel was allowed to dry at $4^{\circ} \mathrm{C}$ and was stored at this temperature between testing. For electrochemical testing, a $70 \mu 1$ volume of the sol gel was mixed with $20 \mu 1$ of the enzyme solution.

A $10 \mu l$ volume of the sol-gel enzyme solution was aliquoted onto the surface of sensor type A. A $5 \mu$ volume was aliquoted on the working electrode of sensor type B and allowed to dry at $4^{\circ} \mathrm{C}$. The sensors were stored in $0.1 \mathrm{M}$ PBS prior to testing

\section{Immobilisation of LOX in a modified BSA Gel}

To $100 \mu 1$ of $0.1 \mathrm{M}$ PBS buffer was added $2 \mathrm{mg}$ of LOx and $20 \mathrm{mg}$ of bovine serum albumin (BSA) powder (Sigma). The solution was stirred gently in a $1.5 \mathrm{ml}$ cuvette. A $1 \mathrm{mg}$ amount of DL-dithiothreitol (Sigma) was added and mixed gently with the enzyme solution. An aliquot of $2 \mu \mathrm{l}$ of $25 \%$ glutaraldehyde (Sigma) was added and mixed gently. A $10 \mu l$ volume was aliquoted in duplicate into the wells of a 96 well COSTAR plate. For electrochemical testing, a $10 \mu \mathrm{l}$ volume was placed on the surface of sensor type $A$. For sensor type B, a $5 \mu 1$ volume was placed on the working electrode area. The gel was then allowed to crosslink for 6 hours at $4^{\circ} \mathrm{C}$ and then washed with PBS buffer to remove any excess enzyme. The sensor was then allowed to dry overnight at $4^{\circ} \mathrm{C}$ for 24 hours. The sensor was stored in 0.1 M PBS buffer at $4^{\circ} \mathrm{C}$ in a closed container.

\section{E. Immobilisation of LOx in a PCS hydrogel}

To $30 \mu l$ of the polycarbamoyl sulphate (PCS) hydrogel (Senslab, Leipzig, Germany) was added $20 \mu \mathrm{l}$ of $1 \%$ (w/v) $\mathrm{NaOH}$ solution to adjust to $\mathrm{pH} 5.5$. A $1 \mathrm{mg}$ amount of $L O \mathrm{Ox}$ $\left(30\right.$ unitsmg $^{-1}$ ) was dissolved in $30 \mu \mathrm{l}$ of $0.1 \mathrm{M}$ PBS. This solution and the PCS hydrogel were mixed together gently.

A $10 \mu 1$ of this solution was aliquoted onto the surface of sensor type $A$, and a $5 \mu$ volume onto sensor type $B$. The sensors were dried overnight and were stored in closed containers in $0.1 \mathrm{MPBS}$ at $4^{\circ} \mathrm{C}$.

\section{F. Enzyme linked Immunosorbent Assay to test Enzyme Activity}

Stability testing, to assess the enzyme activity, was carried out using an enzyme linked immunosorbent assay (ELISA). The ELISA colour reagent consisted of $2 \mu \mathrm{l}$ horseradish peroxidase (HRP), (Sigma) per $1 \mathrm{ml}$ of 3,3',5,5'-tetramethylbenzidine free base (TMB), (Shaw Scientific, Dublin, Ireland). On addition of $0.13 \mathrm{M}$ lactate (Sigma Aldrich) to the immobilised enzyme, $\mathrm{H}_{2} \mathrm{O}_{2}$ was produced. In the presence of $\mathrm{H}_{2} \mathrm{O}_{2}$, HRP catalyses the conversion of TMB in situ to a coloured end product, $1 \mathrm{M}$ $\mathrm{HCl}$ was used to stop the reaction. The soluble yellow end product was quantified by absorbance at $450 \mathrm{~mm}$ using a Kinetic Microplate Reader (Molecular Devices, England). Initially a standard curve of $\mathrm{H}_{2} \mathrm{O}_{2}$ concentration versus absorbance was obtained. From this standard curve it was possible to determine the activity of the immobilised enzyme, based on the amount of $\mathrm{H}_{2} \mathrm{O}_{2}$ produced by the enzyme after a given time interval.

\section{G. Electrochemical Set-up}

A three electrode cell was used. The EG\&G Princeton Applied Research Potentiostat model 363 (Princeton Applied Research, Illinois, USA) was used. The three electrodes were placed in a $30 \mathrm{ml}$ beaker and $25 \mathrm{ml}$ of $0.1 \mathrm{M}$ PBS buffer was added. Each electrode was rinsed in DI water before use. The buffer solution was stirred using E649 Metrohm AG Hersian stirrer (Metrohm, Switzerland),

For sensor type $A$, a planar gold electrode was used as the counter electrode and connected to its relevant position on the potentiostat. For sensor type B, it was possible to connect both the working and counter electrodes using the designed connector. Sensor type $C$ was connected to the potentiostat using the designed package. An external gold counter electrode was needed. The reference electrode used in all cases was a $\mathrm{Ag} / \mathrm{AgCl}$ electrode.

Each sensor was polarised for about 20 minutes in order to reduce the background current to as low as possible.

$3961^{\text {st }}$ Annual International IEEE-EMBS Special Topic Conference on Microtechnologies in Medicine \& Biology October 12-14, 2000, Lyon, France - 0-7803-6603-4/00/\$10.0002000 IEEE 
Increasing concentrations of lactate were added and the current response due to the oxidation of the $\mathrm{H}_{2} \mathrm{O}_{2}$ produced was measured on a Keithley Ammeter. It was possible to monitor the change in current with HPVEE software on a gateway PC. All experiments were carried out at $+575 \mathrm{mV}$ versus a $\mathrm{Ag} / \mathrm{AgCl}$ reference electrode.

\section{RESULTS}

\section{A. Enzyme stability}

The stability of LOx has been assessed in a modified BSA gel and two sol gel matrices using an ELISA method. The activity is defined as the amount of $\mathrm{H}_{2} \mathrm{O}_{2}$ produced per min per mg of enzyme and was monitored over a three month period. A comparison in activity of LOx over a period of time for each immobilisation method discussed is shown in figure 4 . The activity of LOx was not assessed in the PCS hydrogel as only a small amount of the material was available which was used directly for electrochemical testing. LOx showed above average stability when immobilised in sol gel 2 , the enzyme remained active in the sol gel matrix after a period of three months. The enzyme stayed stable for at least 55 days in sol gel 1 and initial activity was much higher than for sol gel 2, 2610 and $400 \mu \mathrm{M} \mathrm{H}_{2} \mathrm{O}_{2}$ per min per $\mathrm{mg}$ of enzyme respectively.

Initial activity of LOX when immobilised in the modified BSA gel was $42.5 \mu \mathrm{M} \mathrm{H}_{2} \mathrm{O}_{2}$ per min per mg of enzyme and the enzyme stayed stable for a period of at least 44 days. Both sol gel 1 and 2 formed a thin rigid enzyme layer on the a planar gold surface. The modified BSA gel also formed a rigid matrix on the gold. A summary of the activity results is presented in Table 1.

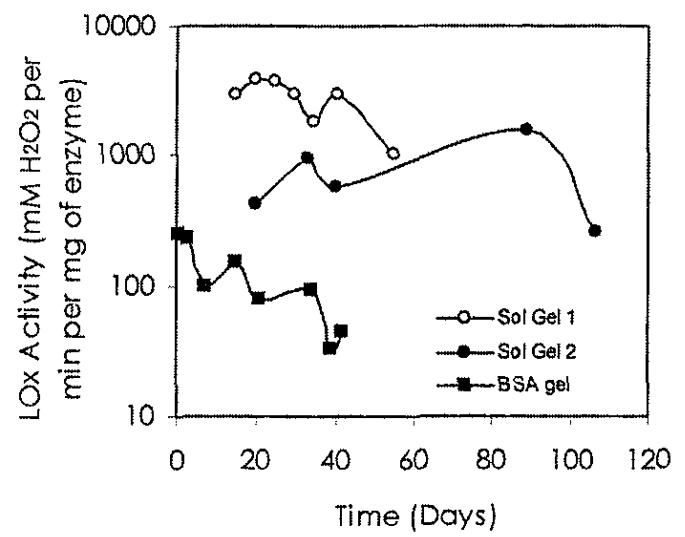

Figure 4 A comparison of the activity of LOx when immobilised in a modified BSA gel and two sol gel matrices.

\section{B Lactate detection}

Initial amperometric detection of lactate has been carried out using all three sensor types. For sensor types $A$ and $B$, a linear range and detection limit for lactate was obtained using sol gel 1 and 2, the modified BSA gel and the PCS hydrogel as immobilisation matrices. A calibration curve for lactate with the containment sensor has been obtained with a simple BSA gel.

Table 1 A comparison of the activity and stability of LOx in the different immobilisation matrices.

\begin{tabular}{|c|c|c|}
\hline $\begin{array}{c}\text { Immobilisation } \\
\text { Method }\end{array}$ & $\begin{array}{c}\text { Stability } \\
\text { (days) }\end{array}$ & $\begin{array}{c}\text { Activity of LOx } \\
\left(\mu \mathrm{M} \mathrm{H}_{2} \mathrm{O}_{2} \text { per min per }\right. \\
\text { mg of enzyme) }\end{array}$ \\
\hline Sol Gel 1 & 77 & 2610 \\
\hline Sol Gel 2 & 107 & 403 \\
\hline Modified BSA Gel & 43 & 42.5 \\
\hline
\end{tabular}

Calibration plots for lactate for the different immobilisation methods with sensor type A are shown in figure 5.

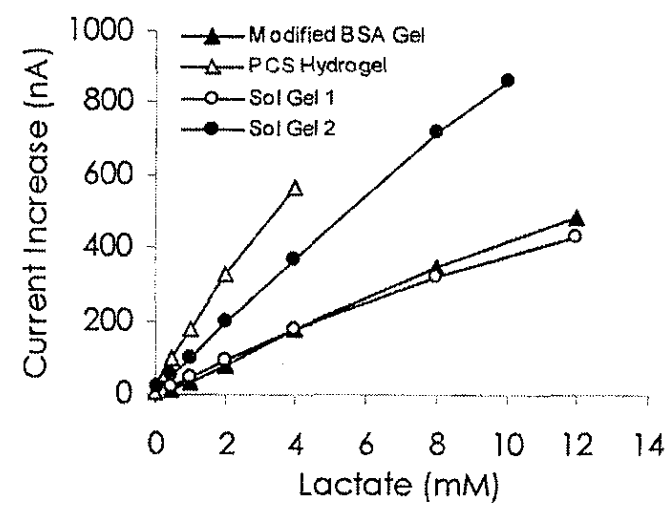

Figure 5 A calibration plot for lactate with sensor type $\mathrm{A}$ using a modified BSA gel, a PCS hydrogel and sol gels 1 and 2 .

The response time was defined as the time for the sensor to reach $90 \%$ of maximum saturation current. Sol gels 1 and 2 showed similar linear ranges of lactate, $0.5-12 \mathrm{mM}$ and 0.1 $10 \mathrm{mM}$ lactate. The response times were 40 and 45 seconds, respectively. This was a quicker response time than for the modified BSA gel, 62 seconds. However the modified BSA gel had a larger linear range for lactate, $0.1-12 \mathrm{mM}$. The PCS hydrogel had a slow response time of 69 seconds, and a small linear range of $0.01-4 \mathrm{mM}$. However the PCS hydrogel exhibited the lowest detection limit for lactate of $0.01 \mathrm{mM}$. A summary of the electrochemical results for sensor $\mathrm{A}$ is shown in table 2 .

Table 2 A summary of electrochemical results obtained using sensor type A.

\begin{tabular}{|l|c|c|c|}
\hline \multicolumn{1}{|c|}{$\begin{array}{c}\text { Immobilisation } \\
\text { Matrix }\end{array}$} & $\begin{array}{c}\text { Linear } \\
\text { Range (mM) }\end{array}$ & $\begin{array}{c}\text { Detection } \\
\text { Limit (mM) }\end{array}$ & $\begin{array}{c}\text { Response } \\
\text { Time (s) }\end{array}$ \\
\hline BSA Gel & $0.05-12$ & 0.05 & 62 \\
\hline PCS hydrogel & $0.01-4$ & 0.01 & 69 \\
\hline Sol Gel 3 & $0.5-12$ & 0.5 & 40 \\
\hline Sol Gel 4 & $0.1-10$ & 0.1 & 45 \\
\hline
\end{tabular}


Similar calibration plots for sensor type B are shown in figure 6.

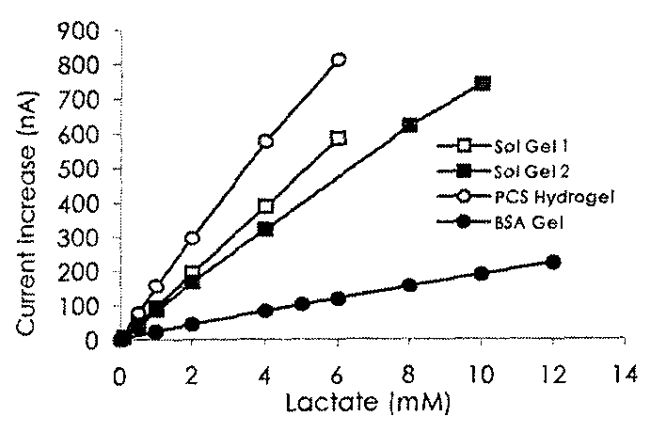

Figure 6 Calibration plots for lactate with sensor type B using a modified BSA gel, a PCS hydrogel and sol gel 1 and 2.

Sol gel 2 had a larger linear range than sol gel 1, 0.1-10mM and $0.1-6 \mathrm{mM}$ respectively. The response times were again similar, 40 and 47 seconds for sol gels 1 and 2, respectively. The modified BSA gel had a linear range for lactate of $0.05-12 \mathrm{mM}$ and a response time of 62 seconds. The PCS hydrogel had a linear range of $0.01-6 \mathrm{mM}$ and a response time of 117 seconds. A summary of the electrochemical results is shown in table 3 .

Table 3 A summary of electrochemical results obtained using

\begin{tabular}{|l|c|c|c|}
\hline \multicolumn{1}{|c|}{ sensor type B. } \\
Matrix \\
BSAbilisan Gel & $\begin{array}{c}\text { Linear } \\
\text { Range (mM) }\end{array}$ & $\begin{array}{c}\text { Detection } \\
\text { Limit } \\
(\mathbf{m M})\end{array}$ & $\begin{array}{c}\text { Response } \\
\text { Time (sec) }\end{array}$ \\
\hline PCS Hydrogel & $0.05-6$ & 0.05 & 117 \\
\hline Sol Gel 3 & $0.1-6$ & 0.1 & 40 \\
\hline Sol Gel 4 & $0.1-10$ & 0.1 & 47 \\
\hline
\end{tabular}

A calibration plot using a simple BSA gel with the cavity sensor is shown in figure 7. The sensor had a linear range for lactate of $0.1-20 \mathrm{mM}$ and a detection limit of $6 \mu \mathrm{M}$.

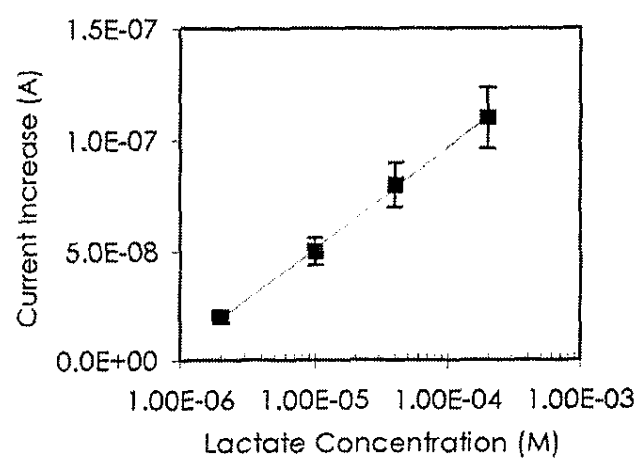

Figure 7 A standard curve for lactate using sensor type $C$ with a simple BSA gel as an immobilisation matrix.

\section{DISCUSSION}

Silicon microsystem technology (MST) refers to a set of deposition and etch processes in which mechanically complex structures can be fabricated on planar substrates. MST has its origins in integrated circuit technology using the techniques of photolithography and thin film deposition. The potential advantages of using silicon MST in biosensors over more conventional methods includes; the ability to create fine electrode patterns having electrode structures with features less than five microns; the ability to form sensor arrays; the possibility of creating integrated devices with increased functionality; and also the potential to integrate microfluidic handling. Using this technology it was thought that the sensor under development here would provide a rapid, cost effective method for manufacgturing an enzyme electrode for lactate.

Different aspects of this technology were applied for the fabrication of different sensor types. Initially a simple gold electrode was fabricated which had a $4 \mathrm{~mm} \times 4 \mathrm{~mm}$ gold on silicon die, which was packaged on a dipstick PCB. The sensor established the compatibility of the gold on silicon substrate for electrochemical detection of lactate. Standard photolithographic techniques were then used for fabrication of sensor type B, which used a three mask process to produce a gold working and counter electrode on the same silicon die. The mask was designed to produce sensors, which had working and counter electrode areas of different sizes and dimensions. The packaging of the sensor on the dipstick $\mathrm{PCB}$ allowed for use of the sensor in aqueous lactate analysis. Sensor die with a working electrode area of $1 \mathrm{~mm}^{2}$ were chosen for lactate detection.

Initial work has also been carried out into the fabrication of a cavity electrode, which uses the process of anisotropic $\mathrm{KOH}$ etching to form a pyramidal cavity on a silicon substrate. It is thought that a containment sensor has the potential to increase both mechanical and chemical stability of the sensor because the biological component is protected by the chip during sensor operation [13].

Investigation was carried out into the several type of immobilisation matrices for the enzyme LOx. Both stability of the enzyme and the compatibility of the matrix was assessed. Any potential immobilisation method should be simple and fast, produce immobilised reagents that are stable and do not leach from the matrix and produce immobilised enzymes that retain their chemical and biochemical activities. The enzyme LOx is known to be quite unstable. Therefore, several immobilisation strategies have been employed here in an effort to increase the long term stability of the enzyme LOx. Initially activity and stability of the enzyme in each immobilisation matrices was first assessed using an ELISA method. The enzyme showed above average stability when immobilised in the sol gel matrices remaining active, stored dry in sol gel 2 for nearly 3 months. The enzyme was seen to remain more active and stable in sol gel 1 and 2 than in the modified BSA gel.

Crosslinking of the enzyme in a BSA gel is a common method of immobilising an oxidase enzyme in the development of amperometric sensors, as it forms a rigid

$398 \quad 1^{\text {st }}$ Annual International IEEE-EMBS Special Topic Conference on Microtechnologies in Medicine \& Biology October 12-14, 2000, Lyon, France - 0-7803-6603-4/00/\$10.0002000 IEEE 
matrix on the surface of the gold. Stability of LOx in the BSA gel remains a problem so a DL-dithiothreitol modifying agent was added to the BSA gel in an effort to stabilise the enzyme. Since this compound is a highly water soluble solid, with little odour and little tendency to be oxidised directly by air, it has proved much superior to the thiols used as protective reagents for sulphydryl groups of the enzyme [14].

Sol gel ceramics has emerged in recent years as a promising new material for biomolecule immobilisation. Immobilised biomolecules have shown enhanced stability when immobilised in a sol gel matrix [15]. Extensive investigation was carried out into sol gel processing conditions in order to find a sol gel that formed a thin rigid layer on the surface of the gold [16]. Both sol gels 1 and 2 formed thin rigid enzyme layer on a planar gold surface while also maintaining enzyme activity over a prolonged period.

Amperometric detection of lactate has been carried out using the three sensor types. The modified BSA, the PCS hydrogel and two sol gel matrices as immobilisation methods were used with sensor type $A$ and $B$ for lactate detection. A simple BSA gel was used for lactate detection using the sensor type $C$. The BSA gel used was the modified BSA gel without the addition of DL-dithiothreitol. Similar trends were observed for sensor type $A$ and $B$. The modified BSA gel has a linear range of up to $12 \mathrm{mM}$ lactate, sol gel 1 exhibits the quickest response time, being slightly quicker than sol gel 2 . The PCS hydrogel while having the lowest detection limit for lactate, has the slowest response time and a poor linear range. Sensor type $C$ showed a linear range of up to $20 \mathrm{mM}$ lactate with a detection limit of $6 \mu \mathrm{M}$. Further testing with the cavity electrode for lactate needs to be carried out using the modified BSA gel and sol gels 1 and 2 as a comparison between the planar and cavity sensors would prove useful.

\section{$V$ CONCLUSION}

A gold enzyme electrode for the detection of lactate has been fabricated on silicon. Both standard planar and micromachining silicon process have been applied for the design of three sensor types. Several immobilisation methods have been investigated in order to improve the long term stability of the enzyme LOx. The enzyme has shown above average stability in a sol gel matrix. From initial amperometric detection of lactate, both a sol gel and a modified BSA gel could be used to immobilise the enzyme. However, the sol gel matrix has shown significantly better long term storage stability.

In order to provide a comparison between the planar and containment sensors, LOx immobilised in a modified BSA gel and sol gel matrices should be investigated with sensor type C. Long term operational stability of each enzyme electrode needs to be assessed. Optimisation of parameters such as buffer $\mathrm{pH}$, operating temperature and matrix effects needs also to be examined, before sensing in real samples can be carried out.

\section{REFERENCES}

[1] Detry B., Nullens W., Cao M. L. and Frans A., "Assessment of the lactate biosensor methodology", Eur. Respir. J., 1998, 11, pp 183187.

[2] Yang Q., Atanasov P., and Wilkins E, "Needle Type Lactate Biosensor" Biosensors and Bioelectronics, 14, 1999, pp 203-210

[3] Meyerhoff C., Bischof F., Mennel F. J, Biosensors \& Bioelectronics, 8, 1993, pp 409-414.

[4] Pfeiffer D., Moller B., Klimes N., Szeponik J. and Fischer S., "Amperometric lactate oxidase catheter for real time lactate monitoring based on thin film technology", Biosens. Biolectron., 12,1997 , pp 539-550.

[5] Rohm I., Genrich M. and Collier U., "Development of ultravioletpolymerizable enzyme pastes: bioprocess applications of screen printed 1-lactate sensors", Analyst, 121, 1996, pp 877-881

[6] Jobst G., Moser I., Varaham M., Svasek P., "Thin film microbiosensors for glucose-lactate monitoring", Anal. Chem., 1996,68 , pp 3173-3179.

[7] Gardner J. W., "Microsensors, principles and applications", J Wiley \& Sons Ltd., England, 1994.

[8] Minagawa H., Nakayama N., Matsumto T. and Narushi l., "Development of long life lactate sensor using thermostable mutant lactate oxidase", Biosensors \& Bioelectronics, 1998, pp 313-320

[9] Haiyang L. and Deng J., "An amperometric lactate sensor employing TTF in nafion film as electron shuttle", Electrochim Acta, 40, 12, 1995 pp 1845-1849.

[10] Palmisano F., Benedetto G. E. and Zambonin C. G., "Lactate amperometric biosensor based on an electrosynthesised bilayer film with covalently immobilised enzyme", Analyst, 122, 1997, pp. 365369.

[11] C. Ramirez Molina, M. Boujtita and N. El Murr "A carbon paste electrode modified by entrapped toluidine blue-O for amperometric determination of -lactate", Anal. Chim. Acta. Volume 401, Issues 1 2, 1999, Pages 155-162.

[12] Lin J. and Brown C. W., "Sol gel glass as a matrix for chemical and biochemical sensing", 16, 4, 1997, pp 200-209.

[13] Perdomo J., Sundermeier $\mathrm{C}$ and Hinkers H., "Containment sensors for the determination of lactate and glucose", Biosensors \& Bioelectron.ics, 14, 1999, pp 27-32.

[14] Cleland W.W, "Dithiothreitol, a new reagent for the SH group", Biochemistry, 3, 1964, pp 480-482

[15] Wang B., Deng Q. and Dong S., "Sol gel glucose sensor based on a organic-inorganic hybrid material", Anal. Chem., 70, 1998, pp 3170-3174

[16] Lillis B., Grogan C., Berney H. and Lane B., "Investigation into immobilisation of lactate oxidase to improve stability", Sensors and Actuators B, 68, 2000, pp 109-114. 